\title{
OBITUARY
}

Acute myeloid leukemia

\section{Clara Bloomfield MD: Queen of AML. Dare to cross her at your risk (May 15, 1942 to March 1, 2020)}

\author{
Robert Peter Gale $\mathbb{C}^{1} \cdot$ Rüdiger Hehlmann ${ }^{2} \cdot$ Andreas Hochhaus $^{3}$
}

Received: 11 March 2020 / Revised: 13 March 2020 / Accepted: 18 March 2020 / Published online: 8 April 2020

(c) Springer Nature Limited 2020

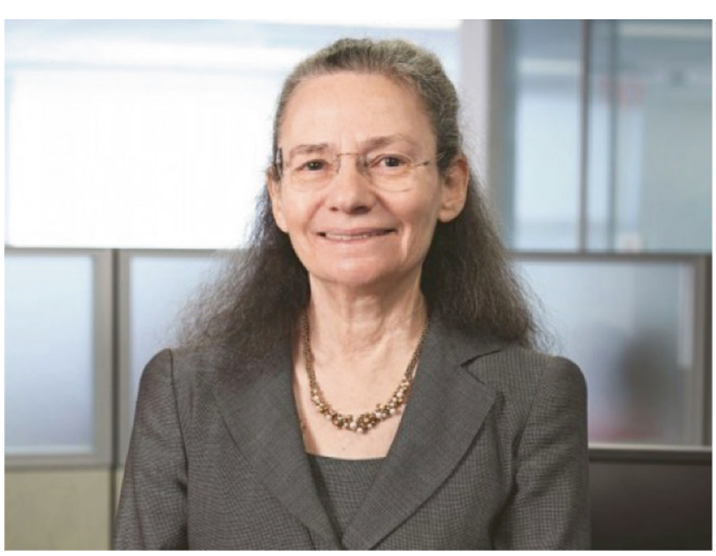

Physicians and scientists interested in acute myeloid leukemia (AML) have lost a shining light with the death of Prof. Clara Bloomfield on March 1, 2020, age 77 years. RPG has known Clara for more than 50 years when I first encountered her at the University of Minnesota. We were coinvestigators for a National Cancer Institute (NCI) sponsored trial of granulocyte transfusions in people with AML and infections. Emil Freireich and colleagues had claimed, based on their usual observational data, that granulocyte transfusions were effective. (Clara was a friend of Freireich but never have two more excitable personalities

This article is co-published in the journals Bone Marrow Transplantation and Leukemia. [https://doi.org/10.1038/s41409-020-0881-x of BMT]

Robert Peter Gale

robertpetergale@alumni.ucla.edu

1 Centre for Haematology, Department of Immunology and Inflammation, Imperial College London, London, UK

2 Universität Heidelberg and ELN-Foundation, Weinheim, Germany

3 Department of Hematology \& Oncology, University Hospital Jena, Jena, Germany been in the same room. I always feared a criticality). Clara wanted convincing evidence of safety and efficacy and agreed to collaborate in a randomized trial. Freireich was horrified but off we went. Not salient to this obituary, but we showed they decreased rather than increased survival. Freireich was not pleased but, no matter, he didn't believe our results anyway. My point in telling this story is every month I flew to Minneapolis for an early morning meeting with Clara at the Kaufman Student Union. One thing I advise anyone from doing is flying overnight in January from balmy Southern California to Minnesota at $-20{ }^{\circ} \mathrm{C}$ and arguing with Clara at an investigator meeting. I survived, barely.

Clara Bloomfield is well known for her more than 50 years of groundbreaking research in blood cancers, especially AML. She helped revolutionize science-based treatment for people with AML by identifying diverse risk cohorts. Her work, in addition to with that of many others like Janet Rowley and Avery Sandberg in the arena of cytogenetics and with Hartmut and Konstanze Döhner and many others in the arena of mutation topography, resulted in the current World Health Organization and European LeukemiaNet (ELN) AML classifications. A Boolean search of MEDLINE with the terms Bloomfield CD and AML identified 198 citations, more than the number of people with AML most hematologists see in a lifetime. Her last AML typescript was published on February 25, 2020, 5 days before her death. That's called dying with your boots on.

Clara Bloomfield was born on May 15, 1942 in New York City. During WWII, the family moved to Washington and after the war to Champaign-Urbana, Illinois, where her parents were faculty members at the University of Illinois. Her mother, Zelda Derber, was a feminist and lawyer and her father, Milton Derber, a labor and industrial relations expert. As a toddler Clara dreamed of Florence Nightingale and at the age of 4 informed her mother she wanted to become a nurse. Her mother replied: "Well dear, that's very nice. But if you want to become a nurse, you might as well become a doctor". And she did. She also recalled that while in grade 
school she had classmates who developed leukemia and, because there was no effective therapy at that time, died.

She began her studies at the University of Wisconsin in Madison but transferred to San Diego to be with her first husband. She graduated San Diego State College in 1964 summa cum laude in biology. As far as is known, this was the only time in her life she lived anywhere with decent weather. Why she loved places like Chicago, Minneapolis, Buffalo and Columbus, Ohio remains a mystery. It may also explain why she married a Finn. Clara went on to study medicine at the University of Chicago graduating in 1968. Her postgraduate training in internal medicine and hematology was at the University of Minnesota where she became the first woman full professor of medicine in 1980 . In 1989, she moved to Buffalo (Chicago not cold enough?) became professor of medicine and chief of the Division of Oncology at the State University of New York at Buffalo and chair of the Division of Medicine at Roswell Park Cancer Institute where she worked with another AML giant, Geoffrey Herzig. They had a brilliant, albeit intriguing relationship given that Geoff was unflappable.

In 1984, she married to Prof. Albert de la Chapelle, a wellknown geneticist and professor from Finland. In 1997, the couple moved to Columbus, Ohio, where she became director of the Division of Hematology-Oncology in the College of Medicine and director of the Ohio State University Comprehensive Cancer Center, a position she held until 2003. Bloomfield was a Distinguished University Professor and senior adviser at Ohio State. She was also a member of the Molecular Biology and Cancer Genetics Program, professor of internal medicine and held an endowed chair in cancer research.

Clara Bloomfield was a force de frappe. Despite what De Gaulle might have thought, France's nuclear arsenal had no chance against her. And the Soviets, toast! Her energy was unlimited and her enthusiasm boundless. She claimed to have been influenced by an editorial by William H. Crosby, a pioneering hematologist, who opined that without effective therapies, treating AML was akin to malpractice because people had no hope of a benefit. She said: "After reading Dr. Crosby's editorial I decided that it would be a good project to attempt to find a cure for AML. And that's what I set about to do".

There is no need to remind readers of Leukemia of the enormous number of cytogenetic abnormalities she described and, more importantly, categorized. She was considered by many the world's authority on how chromosome abnormalities influence treatment and outcome in AML. It was a challenge to absorb $>10 \%$ of the information she presented in a 30-min lecture. Most of us would need a few hours to cover the same material. To say she was a fireball is a huge understatement.
Clara authored many review articles and chapters in leading hematology textbooks and more than 600 peerreviewed articles in major scientific journals including NEJM, Blood, JCO, and Leukemia. She frequently lectured at national and international meetings.

Many junior and senior scientists and physicians spent time or took sabbaticals in Clara's laboratory at Ohio State. Amongst them are some of the most prominent and successful people in leukemia research today. This is perhaps for an academician like Clara her most important legacy.

Clara (we find it impossible to call her Prof. Bloomfield) made extensive contributions to many professional organizations. She served on the Board of Directors of the American Association for Cancer Research (AACR) and American Society of Clinical Oncology (ASCO) and chaired the National Cancer Institute (NCI) Division of Cancer Treatment Board of Scientific Counselors. She was a Chair of the NCI Progress Review Group responsible for defining the national research agenda for leukemia, lymphoma, and myeloma. She was a key member of the AML subcommittee of Cancer and Leukemia Group B for much of her professional career. She also had a special interest in international hematology and was deeply involved with the ELN and the International Association for Comparative Research on Leukemia and Related Diseases with RH and many others.

Clara received many honors, too many to mention here, but including membership in the Institute of Medicine of the National Academy of Sciences (now the National Academy of Medicine), the American Academy of Arts and Sciences, and a Fellow of the AACR Academy. She won many awards, including the Henry M. Stratton Medal from the American Society of Hematology and the David A. Karnofsky Memorial Award from the ASCO. Most recently she received the ELN Merit Award for contributions to international integration of leukemia research.

Following her mother's footsteps, Clara was an ardent feminist relentlessly advancing women in science and medicine through her active mentorship. Woe to the dean or university administrator who dared mentioned sex as a basis for promotion or salary. She mentored more than 100 men and women who are professors at prestigious universities or scientists in leadership positions at the NCI or in industry. Including Michael Caligiuri, Wendy Stock, Richard Larson, and John Byrd.

Clara was $152 \mathrm{~cm}$ (5 feet) but she was a giant, reminiscent of Franco Mandelli and Napoleon. (Francesco Lo-Coco would never let RPG mention Mandelli's height. No comment yet from Napoleon.) Converted to energy per unit mass she would probably outshine the Sun. We shall miss her. Clara said recently: "Unfortunately, clinical research 
has become so over-regulated many people are afraid to question authority. Changing that mindset is a worthy challenge". Bravo! But don't think for a second of challenging the authority of Clara Bloomfield.

Clara was survived by her loving husband of 36 years, Albert de la Chapelle, and her brother Charles Derber.

\section{Compliance with ethical standards}

Conflict of interest The authors declare that they have no conflict of interest.

Publisher's note Springer Nature remains neutral with regard to jurisdictional claims in published maps and institutional affiliations. 